\title{
The Effects of Transcranial Direct Current Stimulation on Functional Movement Performance and Balance of the Lower Extremities
}

\author{
Yeon-Seop Lee, PT, PhD ${ }^{1)}$, Hoe-Song Yang, PT, MSc ${ }^{1)}$, Chan-Joo Jeong, $\mathrm{PhD}^{1}$, \\ Young-Dae Yoo, PT, PhD ${ }^{1)}$, Seung-Hwa JeOng ${ }^{1)}$, OK-Kyoung Jeon ${ }^{1)}$, \\ Hue-Yeon Park ${ }^{1)}$, Hye-Won Shin ${ }^{1)}$ \\ 1) Department of Physical Therapy, Cheongam College: Deokwol-dong, Suncheon-si, Jeonnam 224-9, \\ Republic of Korea. TEL: +82 61-740-7330,FAX: +82 61-740-7339,E-mail: ptyang@scjc.ac.kr
}

\begin{abstract}
Purpose] The aim of this study was to examine the effects of noninvasive transcranial direct current stimulation (tDCS) on functional movement performance and balance of the lower extremities in normal people. [Subjects and Methods] The study randomly divided thirty normal adults into an experimental group and a pseudocontrol group in order to look at the effects of noninvasive tDCS on their agility, power, and balance. Each group also performed a treadmill exercise to evaluate whether brain activation was sustained. [Results] According to the intragroup comparison result, the experimental group showed significant differences in agility and balance, and significant differences occurred in balance in the pseudo-control group. In intergroup comparison, both groups significantly differed in agility and power. [Conclusion] tDCS activates the cerebral cortex, and therefore, is effective in improving functional movements of the lower extremities; it also significantly influences agility among functional movement elements of the lower extremities by maintaining activation of the premotor area during the next movement.
\end{abstract}

Key words: TDCS (Trancecranial Direct Current Stimulation), Agility, Power

(This article was submitted Jun. 15, 2012, and was accepted Jul. 20, 2012)

\section{INTRODUCTION}

The development of brain radiology has provided proof of the effectiveness of tDCS, a noninvasive brain stimulation method $^{1-3)}$. tDCS is a form of neurostimulation, which uses low current delivered directly to the brain area of interest using electrodes placed on the surface of the scalp; anodal stimulation increases the neural network activities of the central nervous system, and cathodal stimulation decreases them. Its application methods and its side effects have been studied for the past few years ${ }^{4-6}$. Currently, tDCS is being studied as a method to improve damaged central nervous systems and patients' neuropathy functions ${ }^{7,8)}$.

Brain activation through tDCS effectively influences motor learning, sensation, cognitive functions ${ }^{9,10)}$, and exercise performance of the upper extremities in CNS injury patients; knowledge of the brain areas influenced by such activation is expanding ${ }^{11-13)}$. Nitsche ${ }^{14)}$ and Madhavan et al. ${ }^{15)}$ reported that adjustment of tDCS intensity and duration may increase motor function and excitability, and in an MRI study, KIM et al. ${ }^{16)}$ observed the possibility of motor adjustment of the lower extremity area. Jeffrey et al. ${ }^{17)}$ noted that a current intensity of $2 \mathrm{~mA}$ increased response time and muscle activity of the lower extremities more than a current intensity of $1 \mathrm{~mA}$ level, and activation of the pre-motor area continued for some time after stimulation ${ }^{7,18-19)}$. Among research on lower extremity motor functions, Ghanim et al. ${ }^{20)}$ reported improved activity of the soleus muscle during sitting and standing motions. Tanaka et a1. ${ }^{21)}$ noted activation of the lower extremity motor area and increased toe strength to grab, and in another study ${ }^{22}$, they observed increased muscle strength of the quadriceps femoris muscle in stroke patients. However, they reported research results obtained using simple tasks.

Based on the effects of tDCS on the lower extremities reported by prior studies, the present study intended to look at the effects of tDCS on agility, power, and balance of the lower extremities when applied to normal people.

\section{SUBJECT AND METHODS}

\section{Subject}

The subjects were 30 normal adults with no medical or neurological abnormalities; they had no respiratory, cardiovascular, orthopedic, or neurological diseases. The experimental method was explained to all subjects, and all consented to participate in this study. During the experiment, all physical activity that could affect the results of this research was limited.

The general characteristics of the subjects are shown in Table 1; there were no significant differences between the two groups in age, height, weight, or body mass index. 
Table 1. Characteristics of study participants

\begin{tabular}{lcc}
\hline & $\begin{array}{c}\text { tDCS group } \\
(\mathrm{n}=15)\end{array}$ & $\begin{array}{c}\text { tDCS(sham) group } \\
(\mathrm{n}=15)\end{array}$ \\
\hline Sex (male/female) & $5 / 10$ & $4 / 11$ \\
Age (years) & $21.8 \pm 1.3$ & $21.4 \pm 1.5$ \\
Height $(\mathrm{cm})$ & $165.5 \pm 9.0$ & $164.3 \pm 11.2$ \\
Weight $(\mathrm{kg})$ & $62.0 \pm 13.2$ & $57.5 \pm 13.4$ \\
BMI & $22.4 \pm 2.5$ & $21.1 \pm 2.9$ \\
\hline
\end{tabular}

$(\mathrm{n}=30)$ Value are Means \pm SD. ${ }^{*} \mathrm{p}<0.05$.

\section{Method}

The subjects were randomly assigned to an experimental group ( 15 people) and a pseudo-control group (15 people), and three items - agility, power, and balance abilitywere measured to evaluate motor functions of the lower extremities. The study used a directed current stimulator, the intensity of which could be adjusted by units of $0.1 \mathrm{~mA}$ (Phoresor II Auto Model PM850, IOPMED, Salt Lake City, UT, USA), and $5 \times 7-\mathrm{cm}$ sponge electrodes $\left(35 \mathrm{~cm}^{2}\right)$, soaked in a $0.9 \%$ NACL solution ${ }^{14}$. Pursuant to the International 10-20 system, the positive electrode was placed at $\mathrm{Cz}$, and the negative electrode was attached to the supraorbital area. In order to examine the effects of tDCS on functional motor performance of the lower extremities, stimulation intensity and application duration were set at $2 \mathrm{~mA}^{17)}$ and 20 minutes $^{23,24)}$. The electrodes were placed in the same areas in both the experimental group and the pseudo-control group. Thirty seconds after the application, stimulation was stopped, and the subjects did not know whether stimulation had been re-applied until 20 minutes had lapsed.

In order to look at whether tDCS application sustained activation of the lower extremity motor cortex, as reported by Antal et al. ${ }^{7)}$, the study applied an additional 20-minute treadmill gait exercise in both the experimental group and the pseudo-control group and examined how activation of the motor cortex affected motor functions of the lower extremities. The gait velocity, $2.8 \mathrm{~km} / \mathrm{h}$, was the gait speed of an ordinary person ${ }^{25}$.

The Biodex Balance System SD (USA, 2005) was used to measure balance. On a static plate, the subjects assumed an athletic, single leg stance with their eyes open; the dynamic level was set at four. They maintained the posture for 20 seconds and took a rest for 10 seconds; the index values were measured three times and averaged. Effective indexes were used to measure the balance overall stability index (OR), anterior-posterior stability index (AP), medial-lateral stability index (ML). Agility Helmas III (NH-3000 FB, Seoul, 2007) of the systemic reactions were measured using the program ${ }^{26)}$. The subjects swiftly leaped from the jump board in response to auditory stimulation-a signal sounded from the measurement device. They performed the motion three times, and the values were averaged. Power Helmas III (NH-3000 Ryu, Seoul, 2007) was used for the standing high jump program ${ }^{26}$. The subjects took a comfortable position standing on the jump board and leaped with both feet at the same time. They were instructed not to bend their knees or their trunk excessively. Measurements were recorded three times, and the values were averaged.

SPSS 18.0 for windows was used to perform the statistical analyses. Repeated measures analysis of variance was used in order to examine the effects of interventions in each group, and the least significant difference test was employed as a post hoc test. The significance level was set at $\alpha=0.05$.

\section{RESULTS}

The effects of tDCS application significantly influenced agility, power, and balance of the lower extremities; agility significantly decreased from the effects of the brain activity, however, on the following treadmill exercise $(p<0.05)$. Regarding the balance abilities in the control group, OR and AP were significantly increased after the tDCS was applied, but treadmill exercise did not affect agility, power, and balance of the lower extremities $(\mathrm{p}<0.05)$ (Table 2$)$. In a comparison between the two groups, the decrease in agility was statistically significant $(\mathrm{p}<0.05)$, but power and balance were not affected.

\section{DISCUSSION}

tDCS may regulate brain activation. It is one of the simple, safe, and cost-effective brain stimulation methods that have clinical uses ${ }^{1,27)}$. Research on invasive and noninvasive nerve stimulation in relation to excitability control of the cerebral cortex is important; research into such kinds of nerve stimulation has investigated them as tools to influence kinesthetic sense perception, functional exercise, and rehabilitation, and generally, to change brain activation potential $^{8,28)}$. Noninvasive tDCS has drawn attention as a potential area of research on neurological reversibility through its application to the premotor area ${ }^{29,30)}$. Although research on tDCS application to the upper extremity areas has been active, research on its application to the lower extremity areas has concerned only response time and single muscle activity ${ }^{17)}$.

This study divided normal subjects into a control tDCS group, to which stimulation was applied for 30 seconds and then stopped, without the subjects' awareness of the fact, and a tDCS group, to which stimulation was applied for 20 minutes. The intention was to look at the effects of tDCS application on agility, power, and balance of the lower extremities. The current intensity of the tDCS was $2 \mathrm{~mA}^{17)}$ and its application duration was 20 minutes. In order to examine whether tDCS application sustained activation of the lower extremity motor cortex, as reported by Antal et al. ${ }^{7)}$, the present study applied treadmill gait training for 20 minutes after tDCS.

In general, increased brain activation translates into increased response time and increased muscle activity. Among research on agility in accordance with tDCS application, Boggio et al. $^{31)}$ reported that performance time decreased in their study of hand response speed, and Kim Joong-sun et al. ${ }^{32}$ ) also reported reduced response times. Jeffery et al. ${ }^{17)}$ observed improved performance and increased response time of the lower extremities in normal 
Table 2. Comparison of functional movement performance and balance data within control and experimental group after intervention

\begin{tabular}{ccrccc}
\hline & & Before tDCS & During tDCS & $\begin{array}{r}\text { After tDCS } \\
\text { (Treadmill) }\end{array}$ & Post hoc \\
\hline \multirow{4}{*}{ EG } & Agility (sec) & $0.4 \pm 0.0$ & $0.3 \pm 0.0$ & $0.3 \pm 0.0^{*}$ & $\mathrm{a}<\mathrm{b}<\mathrm{c}$ \\
& Power (cm) & $25.8 \pm 7.6$ & $26.6 \pm 6.2$ & $28.1 \pm 7.7^{*}$ & $\mathrm{a}<\mathrm{c}$ \\
& Balance (OR) & $2.2 \pm 0.9$ & $1.5 \pm 0.4$ & $1.7 \pm 0.6^{*}$ & $\mathrm{a}<\mathrm{b}, \mathrm{c}$ \\
& Balance (AP) & $1.9 \pm 1.0$ & $1.2 \pm 0.5$ & $1.4 \pm 0.6^{*}$ & $\mathrm{a}<\mathrm{b}, \mathrm{c}$ \\
& Balance (ML) & $0.9 \pm 0.3$ & $0.6 \pm 0.2$ & $0.6 \pm 0.2^{*}$ & $\mathrm{a}<\mathrm{b}$ \\
\hline \multirow{4}{*}{ CG } & Agility (sec) & $0.4 \pm 0.0$ & $0.40 \pm 0.0$ & $0.4 \pm 0.0$ & $/$ \\
& Power (cm) & $24.2 \pm 8.1$ & $24.1 \pm 8.6$ & $24.5 \pm 8.3$ & $/$ \\
& Balance (OR) & $2.3 \pm 0.8$ & $1.6 \pm 0.0$ & $1.4 \pm 0.5^{*}$ & $\mathrm{a}<\mathrm{b}, \mathrm{c}$ \\
& Balance (AP) & $1.9 \pm 0.0$ & $1.1 \pm 0.3$ & $1.1 \pm 0.4^{*}$ & $\mathrm{a}<\mathrm{b}, \mathrm{c}$ \\
& Balance (ML) & $1.0 \pm 0.0$ & $0.8 \pm 0.3$ & $0.7 \pm 0.4$ & $/$ \\
\hline
\end{tabular}

$(\mathrm{n}=30)$ Value are Means $\pm \mathrm{SD} . * \mathrm{p}<0.05$. EG; experimental group, $\mathrm{CG}$; control group, OR; overall stability index, AP; anterior-posterior stability index, ML; medial-lateral stability index.

subjects. According to the present study results, tDCS application may effectively enhance normal people's agility, and the resulting activation of the motor cortex has a sustained influence on treadmill gait, as asserted by Antal et al. ${ }^{7)}$.

No previous research directly examined power among investigations on lower extremity motor function in accordance with tDCS application. In a study of a single muscle in the lower extremities, Ghanim et al. ${ }^{20)}$ reported increased strength of the soleus muscle during sitting and standing motions. Tanaka et al. ${ }^{21)}$ noted that stimulation of the lower extremity motor area led to increased muscle strength of a single joint, activation of dorsiflexor muscles, and increased toe strength to grab. Tanaka et al. ${ }^{22)}$ observed increased muscle strength in the quadriceps femoris in stroke patients. In the present study, tDCS application did not significantly improve normal subjects' power, but did increases the strength of a single muscle of a single joint; activation of the motor cortex did not influence power, unlike the study result reported by Antal et al. ${ }^{7}$.

The experimental group and the control group obtained the same level of improvement in their lower extremity balance, suggesting no direct effects of tDCS on lower extremity balance. Treadmill gait training was not associated with lower extremity balance.

As asserted by previous studies, tDCS activates the premotor area of the cerebral cortex and has positive influences on functional movements of the lower extremities. Such activation maintains activation of the premotor area during the performance of the next exercise, and therefore, significantly influences functional movements of the lower extremities. Noninvasive brain activity and motor ability to activate the brain less effective for elderly patients with brain injury or to improve motor function in a way that can be used, and the increase of these movements are more efficient than the existing methods do not further the study on the Improvement of motor performance and improve lower extremity function should continue.

\section{REFERENCES}

1) Kwon $\mathrm{YH}$, Ko $\mathrm{MH}$, Ahn $\mathrm{SH}$, et al.: Primary motor cortex activation by transcranial direct current stimulation in the human brain. Neurosci Lett, 2008, 435: 56-59. [Medline] [CrossRef]

2) Furubayashi T, Terao Y, Arai N, et al.: Short and long duration transcranial direct current stimulation (tDCS) over the human hand motor area. Exp Brain Res, 2008, 185: 279-286. [Medline] [CrossRef]

3) Vines BW, Schnider NM, Schlaug G: Testing for causality with transcranial direct current stimulation: Pitch memory and the left supramarginal gyrus. Neuroreport, 2006, 17: 1047-1050. [Medline] [CrossRef]

4) Vandermeeren Y, Jamart J: Effect of tDCS with an extracephalic reference electrode on cardio-respiratory and autonomic functions. BMC Neurosci, 2010, 11: 38. [Medline] [CrossRef]

5) Abraham P: Arul-Anandam, Colleen Loo, Perminder Sachdev: Transcranial direct current stimulation - what is the evidence for its efficacy and safety? Med-Rep, 2009, 1: 58.

6) Siebner HR, Lang N, Rizzo V, et al.: Preconditioning of low-frequency repetitive transcranial magnetic stimulation with transcranial direct current stimulation: evidence for homeostatic plasticity in the human motor cortex. J Neurosci, 2004, 24: 3379-3385. [Medline] [CrossRef]

7) Antal A, Terney D, Poreisz C, et al.: Towards unravelling task-related modulations of neuroplastic changes induced in the human motor cortex. Eur J Neurosci, 2007, 26: 2687-2691. [Medline] [CrossRef]

8) Webster BR, Celnik PA, Cohen LG: Noninvasive brain stimulation in stroke rehabilitation. NeuroRx, 2006, 3: 474-481. [Medline] [CrossRef]

9) Fregni F, Boggio PS, Mansur CG, et al.: Transcranial direct current stimulation of the unaffected hemisphere in stroke patients. Neuroreport, 2005, 16: 1551-1555. [Medline] [CrossRef]

10) Kincses TZ, Antal A, Nitsche MA, et al.: Facilitation of probabilistic classification learning by transcranial direct current stimulation of the prefrontal cortex in the human. Neuropsychologia, 2004, 42: 113-117. [Medline] [CrossRef]

11) Hummel F, Celnik P, Giraux P, et al.: Effects of non-invasive cortical stimulation on skilled motor function in chronic stroke. Brain, 2005, 128: 490-499. [Medline] [CrossRef]

12) Grüner U, Eggers $C$, Ameli M, et al.: $1 \mathrm{~Hz}$ rTMS preconditioned by tDCS over the primary motor cortex in Parkinson's disease: effects on bradykinesia of arm and hand. J Neural Transm, 2010, 117: 207-216. [Medline] [CrossRef]

13) Pereira JB, Junqué C, Bartrés-Faz D, et al.: Tolosa EModulation of verbal fluency networks by transcranial direct current stimulation (tDCS) in Parkinson's disease. Brain Stimul, 2012, 22

14) Nitsche MA, Cohen LG, Wassermann EM, et al.: Transcranial directcurrent stimulation: State of the art. Brain Stimulat, 2008, 1: 206-223. [CrossRef]

15) Madhavan S, Rogers LM, Stinear JW: A paradox: after stroke, the non-lesioned lower limb motor cortex may be maladaptive. Eur J Neurosci, 2010, 32: 1032-1039. [Medline] [CrossRef]

16) Kim YH, Jo JM, Ohn SH, et al.: Enhancing the working memory of stroke patientsusing tDCS. Am J Phys Med Rehabil, 2010, 88: 404-409. 
17) Jeffery DT, Norton JA, Roy FD, et al.: Effect of transcranial direct curren stimulation on the excitability of the leg motor cortex. Exp Brain Res, 2007, 182: 281-287. [Medline] [CrossRef]

18) Nitsche MA, Liebetanz D, Lang N, et al.: Safety criteria for transcrania direct current stimulation (tDCS) in humans. Clin Neurophysiol, 2003, 114: 2220-2222. [Medline] [CrossRef]

19) Priori A: Brain polarization in humans: a reappraisal of an old tool for prolonged non-invasive modulation of brain excitability. Clin Neurophysiol, 2003, 114: 589-595. [Medline] [CrossRef]

20) Ghanim Z, Lamy JC, Lackmy A, et al.: Effects of galvanic mastoid stimulation in seated human subjects. J Appl Physiol, 2009, 106: 893-903. [Medline] [CrossRef]

21) Tanaka S, Watanabe K: Transcranial direct current stimulation-a new tool for human cognitive neuroscience. Brain Nerve, 2009, 61: 53-64. [Medline]

22) Tanaka S, Takeda K, Otaka Y, et al.: Single session of transcranial direct current stimulation transiently increases knee extensor force in patient with hemiparetic stroke. Neurorehabil Neural Repair, 2011, 25: 565-569. [Medline] [CrossRef]

23) Kang EK, Paik NJ: Effect of a tDCS electrode montage on implicit motor sequence learning in healthy subjects. Exp Transl Stroke Med, 2011, 3:4

24) Perry J: Gait analysis: Normal and Pathological Function (2nd ed). SLACK. Inc, 2010

25) Kim EJ, Kim SM, Lim JT, et al.: A comparison between children at the eco early childhood education center and the general childhood education center children's physique and physical fitness. Korean Soc For Eco Early Child Educ, 2010, 9: 51-70.
26) Hauck M, Baumgartner U, Hille E, et al.: Evidence for early activation of primary motor cortex and SMA after electrical lower limb stimulation using EEG source reconstruction. Brain Res, 2006, 1125: 17-25. [Medline] [CrossRef]

27) Antal A, Brepohl N, Poreisz C, et al.: Transcranial direct current stimulation over somatosensory cortex decreases experimentally induced acute pain perception. Clin J Pain, 2008, 24: 56-63. [Medline] [CrossRef]

28) Gandiga PC, Hummel FC, Cohen LG: Transcranial DC stimulation (tDCS): a tool for double-blind sham-controlled clinical studies in brain stimulation. Clin Neurophysiol, 2006, 117: 845-850. [Medline] [CrossRef]

29) Lang N, Siebner HR, Ernst D, et al: Preconditioning with transcrania direct current stimulation sensitizes the motor cortex to rapid-rate transcranial magnetic stimulation and controls the direction of aftereffects. Biol Psychiatry, 2004, 56: 634-639. [Medline] [CrossRef]

30) Iyer RB, Silaghi-Dumitrescu R, Kurtz DM, et al.: High-resolution crystal structures of Desul fovibrio vulgaris (Hildenborough) nigerythrin: facile, redox-dependentir on movement, domain inter face variability, and peroxidase activity in the rubrery thrins. J Biol Inorg Chem, 2005, 10: 407-416. [Medline] [CrossRef]

31) Boggio PS, Bermpohl F, Vergara AO, et al.: Go-no-go task performance improvement after anodal transcranial DC stimulation of the left dorsolateral prefrontal cortex in major depression. J Affect Disord, 2007, 101: 91-98. [Medline] [CrossRef]

32) Kim JS, Nam SH, Jo IS: The effects of transcranial direct current stimulation in motor performance of serial reaction time task. Korean Soc Phys Ther, 2010, 22: 103-108. 